\title{
The Problem of Re-Entry to a High-Employment Economy
}

\author{
An Address by DARRYL R. FRANCIS, President, Federal Reserve Bank of St. Louis, \\ at the Memphis State University Management Day Dinner, \\ Memphis, Tennessee, March 29, 1973"
}

T IS GOOD to have this opportunity to discuss with you some of my views on the problems we face as the economy approaches a high-employment level of activity. With the tremendous expansion of economic activity last year following the lackluster period of 1971 , there is little doubt that high employment is now at hand. Indicators of both current and future developments reflect a vigorous business expansion across a broad front.

Economic expansion cannot continue at the advanced pace of recent months, and most economists foresee some slowing later this year. I would interpret a slowing in the pace of economic activity as we reach a high-employment stage as a healthy sign. However, for various reasons, which I will discuss shortly, a slowing in the rate of increase of output may well be accompanied by an acceleration in the rate of increase of prices.

If these developments occur, I am greatly concerned that we may see a further expansion of the Government's role in economic stabilization. In the past, calls have been made for more Government spending to stimulate real economic growth on one hand, while on the other, price and wage controls have been used in attempts to arrest inflation. It is my view that the reemergence of such policies in the near future would be a serious mistake, even as we continue to feel the ill winds of earlier Government excesses. I continue to believe that appropriate structural and aggregate demand policies with proven credentials are standing by, ready for intelligent implementation, to ease the costs of the winding-down process. I will discuss them in some detail.

\section{PUSWES CONDWMUNS}

First, let me review the current business situation and recent policy actions. Signs of continuing expan-

\footnotetext{
This presentation has been revised to take into account the
} most recent available data. sion are evident everywhere. Retail sales and personal income are well above year-earlier levels. Housing starts continue at a pace far more rapid than foreseen by most experts. Plant and equipment expenditures are projected by the Commerce Department to increase about 13 percent in 1973 , compared to 9 percent last year and 2 percent in 1971.

Output gains have been exceptional. Industrial production in April was 9 percent above the year-earlier level. Real product increased about 7.5 percent in the year ending fourth quarter 1972, and has registered an 8 percent rate of growth in the first quarter of this year. By comparison, the trend growth rate of both industrial production and real product over the past twenty years has been approximately 4 percent per year.

The recent expansion of output has been accompanied by a significant decline in the unemployment rate from almost 6 percent in March of last year to the current rate of about 5 percent. Employment growth has been exceptionally rapid, but an equally exuberant expansion in the labor force has hampered further declines in the unemployment rate. Currently, the ratio of all employed workers to the population of working force age is higher than at any time in the twenty-year period preceding 1968, a period which includes several episodes of unemployment rates at or near the 4 percent level.

One interesting aspect of the current 5 percent unemployment rate in the face of a large increase in the number of employed individuals is the rapid rise in such relatively unskilled workers as teenagers, part time employees, and military veterans. The 5 percent overall unemployment rate is partially masking the fact that there are shortages of many skilled workers including plant electricians, machinists, and certain types of mechanics and engineers. Also, average weekly hours of work in the manufacturing sector are 
about as high as in 1969 , a year when the unemployment rate averaged only 3.5 percent.

High rates of plant and equipment capacity utilization are being experienced in a number of important industries. The auto and rubber industries report that extensive overtime operations have pushed their capacity utilization rates above levels desired for maximum efficiency. For all manufacturing industries, the utilization rate is about 86 percent, not much different than the high-employment rate of the middle 1960 s.

The fall in the unemployment rate in recent months has been accompanied, unfortunately, by an acceleration in the inflation rate. Consumer prices increased at a 6.6 percent rate in the six-month period ending in April, compared to a 3.7 percent rate of increase in the preceding six months. Wholesale prices accelerated to a 17.3 percent annual rate in the past six months, triple the rate of the preceding six-month period.

Adverse short-run supply conditions in the agricultural sector undoubtedly contributed to the recent price acceleration, but it will be some time before these conditions are effectively corrected. Phase II price and wage controls may have held down measured prices in some areas in 1972 (although this is uncertain), but Phase III will be marked by much stronger wage pressures as a result of more union bargaining than in 1972 and stronger demand pressures, as reflected in recent income and employment gains. Of greatest importance in contributing to these demand pressures has been the recent expansionary stance of monetary and fiscal policy actions.

\section{STABILATION POLICY ACTONS}

Both monetary and fiscal actions were restrictive in 1969 in order to slow inflationary pressures, but since that time they have become considerably more stimulative. The rate of growth of the money supply increased in each succeeding year from 4.2 percent in 1969 to 7.4 percent in 1972. In comparison, the longrun trend rate of money supply growth, over the past two decades, has been only about 3 percent per year. The Federal deficit (on a national income accounts basis) expanded from $\$ 1.3$ billion in fiseal year 1970 to $\$ 21.1$ billion in fiscal year 1972 .

Even if stabilization policies were to become moderately restrictive in 1973 - and evidence at this time is inconclusive - the lagged effects of earlier expansionary actions would likely contribute to a continued movement of the economy toward high employment in the present year. Whether the so-called "magic" unemployment figure of 4 percent would be reached is another question.

You will notice that I have been talking about a "high" employment economy rather than one of "full" employment. The reason is that "full" employment is often taken to refer to some specific rate of unemployment, such as the 4 percent level. I believe that attempts to achieve numerical targets of this sort have probably led to as many problems as they have solved. The single-minded pursuit of virtually any goal often results in undesiralyle side effects. In this case, zealous pursuit of a target rate of unemployment, without adequate recognition of the lags in effect of monetary policy, has often been followed by inflationary pressures.

What is an acceptable target for unemployment? I agree with the Council of Economic Advisers that instead of a number, this "policy goal is a condition in which persons who want work and seek it realistically on reasonable terms can find employment."

There is no doubt that some unemployment will exist even under these conditions as individuals seek the most "reasonable terms" compatible with their individual job skills. This period of search is heavily influenced by the availability of job information, the level of education and skill attained, and the extent of such job hindrances as the minimum wage, union nonprice job discrimination, and excessive compensation for those remaining unemployed. Because the importance of these factors varies greatly over time, it is not possible to say that a feasible goal for the unemployment rate in 1973 is the same as was observed a decade or two ago.

Once these structural impediments to employment are considered, the "high-employment" unemployment rate which emerges is called the "normal" or "natural" rate of unemployment. The unique feature of the concept of a "natural" unemployment rate is that it is consistent with a stable rate of inflation. Unemployment rates above the natural rate are usually associated with price decelerations and unemployment rates below it are generally related to price accelerations. Clearly, if labor market constraints could be lessened so that demand price pressures would emerge at say, a 3 percent unemployment rate instead of a 5 percent rate, the whole economy would profit. Historically,

TThe Annual Report of the Council of Economic Advisers, 1973 (CEA Report), p. 74. Italies supplied. 
however, the evidence suggests that this variable natural rate of unemployment has probably been closer to 5 percent than 3 percent.

Therein lies the problem. Past experience has taught us that expansionary monetary and fiscal policies can be used to reduce the unemployment rate for a period of time below the natural rate; however, experience has also shown that the cost of doing so has been accelerating inflation.

I want to be very clear in emphasizing this point. Socially and politically, an unemployment rate in the neighborhood of 5 percent has come to be viewed as unacceptable. Thus, there is great incentive to take action to reduce $i t$. The types of actions that would reduce the natural rate of unemployment are very difficult to implement, and slow to take effect since they involve fundamental improvements in the structure of our labor markets.

In contrast, stimulative monetary actions are relatively easy to implement and operate with a fairly short and predictable lag. You can imagine the temptations and the pressures on monetary policymakers to take actions that would result in a near-term reduction in unemployment, even if it is fully recognized that the results of having done so will be an acceleration in the rate of inflation sometime in the future. My view of the lags in the effect of monetary actions on production, employment, and prices is such as to imply that it is necessary to begin reducing the amomt of monetary stimulus well in advance of observing something approximating full employment and full utilization of capacity.

By analogy, I might characterize my view as being similar to the situation faced by astronauts returning to earth from a flight in space. You all are well aware that, as our spacemen begin to get closer to home, the earth's gravitational pull causes their speed to accelm erate. Yet, they also begin to experience increased friction when they encounter the earth's atmosphere. Thus, it is necessary for them to fire their retro-rockets at a fairly early stage of the re-entry in order to avoid achieving too much speed and generating too much heat.

To a space scientist, as well as the general public, this seems to be a logical action to take at the time. But in the re-entry phase of economic stabilization, it seems much less obvious to most observers, including Government officials, that the monetary authorities should fire their retro-rockets, and begin to reduce the amount of monetary stimulus at a time when unemployment remains at a fairly high level.
This illustration is my way of expressing the view that the chief role of policymakers is to avoid plunging the economy sharply down one path and then correcting sharply in another direction. It is my belief that the economy is basically stable and, if given a chance, would not need the nimble talents required of an astronaut whose on-board computer has failed during the descent to earth. In other words, despite repeated calls for moderation, stop-and-go performance has been the effect of so-called "stabilization" policies for years.

Now let me turn to a few remarks regarding a constraint on the ability of monetary authorities to follow the approach 1 have suggested. A major factor influencing central bank operations at various times is changes in the Federal Government's budget position. When the Federal budget is in surplus there need not be much of a problem, but at times when deficits occur, as they have in 14 of the past 20 fiscal years, the monetary policymakers feel obligated to take this into consideration in arriving at their policy decisions.

The problem can be put quite simply: the short-run effect of the issuance of Govermment bonds to finance deficits is to increase market interest rates. Since interest rate movements have usually weighed heavily in the Federal Reserve decision-making process, this upward pressure on interest rates is met with resistance in the form of open market purchases for the accounts of Federal Reserve Banks. Often an undesired, but very important, side effect is the increase in the money supply generated by such actions.

Thus, the dilemma of the monetary policymaker in these deficit situations is deciding whether to risk more monetary expansion than is consistent with reasonable price stability, or accept a period of financial stress with its accompanying negative effects on the real sector. The enactment of realistic tax programs to cover burgeoning Government expenditures would first remove an unnecessary constraint on monetary stabilization actions, and second, focus the taxpayers' attention more clearly on the costs of Federal programs.

\section{ALTENATIV APPTOACHES}

As re-entry into high employment occurs, as it inevitably must with an economy which has been expanding in real terms at a 7 percent rate relative to a 4 percent long-term potential, the questions arise as to when, and how hard, the retro-rockets should be fred. At least, these issues arise if you agree that very stimulative monetary and fiscal actions cannot be pursued indefinitely. 
One of the best ways to insure that highly stimulative monetary actions will not be maintained too long would be to keep a lid on Government spending. In that way, the deficits which have indirectly influenced monetary expansion in recent years could be minimized. Independent of stabilization actions, the expanded role of Govermment spending in the U.S. econ" omy is due for careful re-examination. Government spending on goods and services relative to the total economy doubled from 11 percent to 22 percent in the twenty-five year period ending in 1972 .

Once the time for less expansive policy actions is identified, I see at least three approaches to "firing the rockets." One would be to adopt a very restrictive stance and hold it for an extended period of time. This has been done on previous occasions, with economic recession the usual consequence. However, in the present circumstances, 1 do not think such a severe policy reversal is yet required. There is still time to make a mid-course correction toward more moderate actions.

A second approach wottld be to move gradually in the direction of long-term fiscal and monetary stabilization targets consistent with long-run price stability and a high level of employment. A third alternative is to move immediately to the long-run target. At this time, the lag patterns associated with the current direction of the economy into the high-employment stage and the response of the economy to a proposed policy shift are under study. I can only say that I favor neither the extreme of maintaining accelerated policy stimulus, nor a policy which would slow the economy to the recession point.

I must point out that any permanent slowing of the rate of monetary expansion would be accompanied by temporary adjustment costs in the form of a slowing in the rate of growth of output and employment. The costs would be less now, however, than if the adjustment period were postponed.

Finally, I would like to conclude with the observation that monetary and fiscal actions need not "go it alone" as we re-enter the critical high-employment stage. There are numerous legislative actions which could be taken to lower unemployment at the same time orthodox stabilization actions become less stimulative. Provisions for additional job training and less costly job information, modification of the minimum wage which tends to keep teenage unemployment so high, revision of our social welfare policies to create maxinum incentives to work, and curbs on business and labor non-price job diserimination are some of the possible measures.

So far as inflation is concerned, the most appropriate structural measures for the current situation are those which increase the supply of goods and services. Some of the actions along this line which have already been taken include the temporary suspension of oil import quotas, meat import quotas, crop acreage allotments, and the release of Government stockpiles of certain goods. There exist far more supply restrictions which could be eliminated, thereby contributing significantly to the battle against inflation.

With regard to wage and price controls in a high employment economy, again I agree with the Council of Economic Advisers who noted in 1970 that

Experience with [direct wage and price measures] in other countries has been remarkably consistent. In some cases success in holding down wage settements or price increases has been achieved in certain industries. There is usually a period in which these programs may have some overall deterrent effect, though evidence here is less certain. After an interval, how ever, there is a point at which accumulating pressures make the programs ineffective. American experience conformed to this pattern."

In closing, I would like to stress that the current high-employment re-entry problem exists only because of earlier stop-and-go excesses. A continuation of go actions would bring about a replay of the rapidly accelerating prices of the late $1960 \mathrm{~s}$, except that the acceleration would occur at higher levels in the 1970s. The adoption of severe stop policies would produce another major recession. If we can adopt and maintain policies geared to long-run considerations, the highemployment re-entry problem could become only a memory of the past.

${ }^{2} 1970$ CEA Report, pp. 23-24.

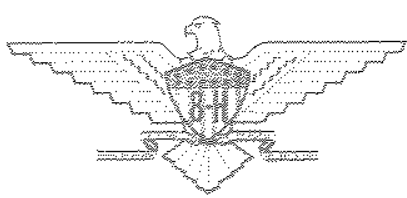

Page 14 